\title{
The Immediate Effects of Graston Instrument-Assisted Soft-Tissue Mobilization and Self-Stretching on the Muscular Properties of the Gastrocnemius in Athletes
}

\author{
Ho-Seong Kang ${ }^{\dagger}$, PT • Jung-Hoon Lee, PT, $\mathrm{PhD}^{1}$
}

Sports Rehabilitation Center, Dongeui Institute of Technology, ${ }^{1}$ Department of Physical Therapy, College of Nursing and Healthcare Sciences, Dongeui University

Received: August 8, 2020 / Revised: August 10, 2020 / Accepted: September 21, 2020

(C) 2020 J Korean Soc Phys Med

\section{| Abstract |}

PURPOSE: This study examined the immediate effects of Graston instrument-assisted soft-tissue mobilization(GIASTM) and self-stretching on the muscular properties of the gastrocnemius in athletes.

METHODS: Thirty subjects (All in their $20 \mathrm{~s}$ ) were distributed randomly and evenly into two groups of 15 each: GIASTM and stretching. The subjects had no history of gastrocnemius damage in the previous three months. The muscle tone, stiffness, elasticity, and mechanical stress relaxation time (MSRT) of the gastrocnemius were blind-tested.

RESULTS: The GIASTM group showed significant changes in all categories, while only MSRT changed significantly in the self-stretching group after intervention. A comparison of the two groups revealed significant differences in stiffness, elasticity, and MSRT (Time required for the muscle to recover after distortion after intervention in the GIASTM group.

†Corresponding Author : Ho-Seong Kang abell7976@gmail.com, https://orcid.org/0000-0002-5333-7833 This is an Open Access article distributed under the terms of the Creative Commons Attribution Non-Commercial License (http://creativecommons.org/licenses/by-nc/3.0) which permits unrestricted non-commercial use, distribution, and reproduction in any medium, provided the original work is properly cited.
CONCLUSION: In this study, significant decreases in muscle tone and stiffness, as well as significant increases in elasticity, were observed in the gastrocnemius of the GIASTM group. On the other hand, sSelf-stretching showed significant differences in MSRT. Therefore, GIASTM is more effective in the recovery of the gastrocnemius muscle from fatigue than self-stretching. This study suggests that GIASTM can help prevent damage to the gastrocnemius in athletes and contribute to their training and rehabilitation programs.

Key Words: Mobilization, Stretching, Gastrocnemius

\section{Introduction}

Athletes are relatively more susceptible to musculoskeletal diseases than the general population because of the high intensity of movements and repetitive motions [1]. Athletes can overuse the soft tissue during athletic events, and the control of musculoskeletal pain caused by overactive muscles has a huge effect on their performance [2]. The gastrocnemius muscle is usually dam-aged in sports, such as sprinting, jump-based track and field events, soccer, and weightlifting, or in any activity where athletes must endure strong resistance [3]. Gastrocnemius damage can lead to postural changes, pain, and restricted range of motion. 
Table 1. General Characteristics of the Subjects

\begin{tabular}{cccccc}
\hline & $\mathrm{N}$ & Age (year) & Weight $(\mathrm{kg})$ & Height $(\mathrm{cm})$ & BMI (score) \\
\hline GIASTM & 15 & $22.13 \pm 1.80$ & $68.67 \pm 10.73$ & $177.06 \pm 4.54$ & $22.12 \pm 2.97$ \\
Stretching & 15 & $22.80 \pm 1.65$ & $75.60 \pm 12.48$ & $177.33 \pm 10.13$ & $22.76 \pm 2.34$ \\
$p$ & & 1.000 & .530 & .735 & .234 \\
\hline
\end{tabular}

Therefore, a range of methods, such as stretching, instrumentassisted soft-tissue mobilization (IASTM), self-myofascial release techniques, and antagonist muscle fortification, are used to prevent gastrocnemius damage [4-6]. Stretching improves the range of motion of the joints and is performed widely before weight-training or cardio workouts to warm up all the muscles and joints. Static, ballistic, and proprioceptive neuromuscular facilitation methods are commonly used for stretching [7-9].

Graston-instrument-assisted soft-tissue mobilization (GIASTM) is an IASTM that uses the Graston technique and improves muscle stiffness and range of motion to restore the flexibility of the muscles [10]. GIASTM is one of the IASTMs suitable for treating inflammatory disease and can rearrange tissues, reduce pain, and improve functional movements [11]. Howitt et al. reported that four weeks of GIASTM fully restored the range of motion of the thumb [12]. Hammer and Pfefer reported reduced back pain and improved hamstring muscle flexibility in patients with back pain caused by compartment syndrome after applying GIASTM to the vertebral hamstring muscles and myofascia twice a week for three weeks [13].

Although previous studies examined the effects of self-stretching or GIASTM on muscle flexibility and strength, no studies have been conducted on the gastrocnemius of athletes. This study compared the changes in the muscular properties, where GIASTM and self-stretching could affect gastrocnemius damage, and examined its effects on gastrocnemius flexibility and muscular strength.

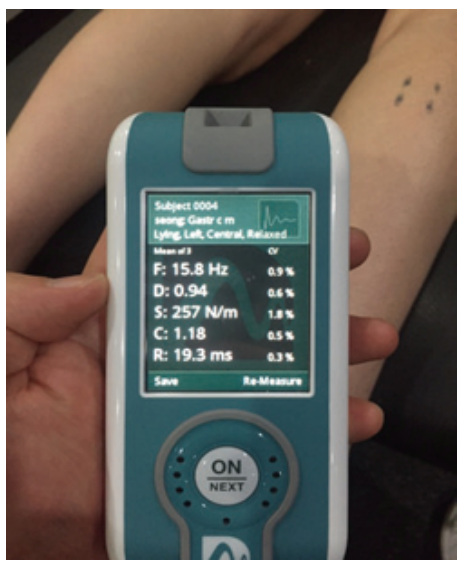

Fig. 1. MyotonPRO (AS).

\section{Methods}

\section{Participants}

Thirty volunteers (All in their $20 \mathrm{~s}$, male) who participated in this study were active in sports, such as soccer (16), taekwondo (8), judo (2), badminton (2), and baseball (2), and had no history of gastrocnemius damage in the previous three months. Before the study, the participants signed an informed consent form by the Research Ethics Committee. Table 1 lists the characteristics of the participants.

\section{Procedures}

The 30 subjects (All in their $20 \mathrm{~s}$ ) were distributed randomly and evenly into two groups of 15 each: GIASTM and stretching. The muscle tone, stiffness, elasticity, and mechanical stress relaxa-tion time (MSRT) of the gastrocnemius were blind-tested by an evaluator (By a physiotherapist), who was unaware of whether the subjects used GIASTM or static stretching (Fig. 1). 


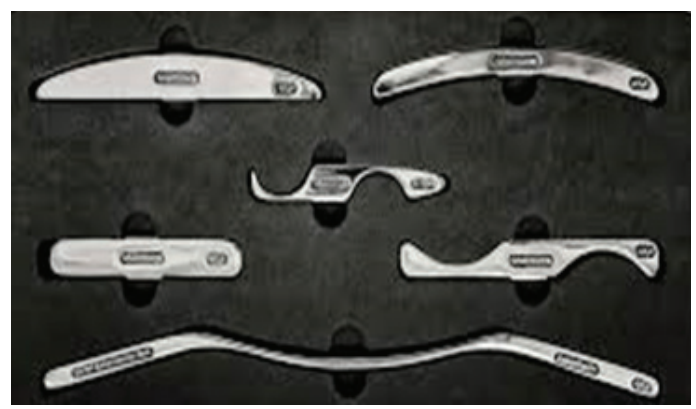

Fig. 2. Graston instruments (Graston technique).

\section{Measurement}

MyotonPRO (MyotonPRO, AS, Estonia), which is used to measure the muscle tone at rest or dur-ing contraction, can measure the tissue's biomechanical properties easily and swiftly in different positions [14] (Fig. 2). MyotonPRO provides the following biomechanical parameters: (1) muscle tone, which indicates the blood flow into the muscle and, shows the state of resting tension without other mechanical contractions as frequency $(\mathrm{Hz})$; (2) stiffness, which shows the resistance level at muscle contraction or the resistance level of the muscle when the muscle itself is distorted by an external force; (3) elasticity, which shows the recovery of the muscle shape after distortion [14]; and (4) MSRT, which shows the time required for a muscle to recover after distortion caused by an external force or contraction. This study applied GIASTM and self-stretching to the median belly of the gastrocnemius muscles [15], which could be damaged easily and shows the highest reliability in a reliability test using a muscle tension tester [16]. Previous studies reported that the correlation coefficient of the intra-rater reliability of the MyotonPRO was high, at .94 to .99 [17].

\section{Intervention}

GIASTM was performed by a physical therapist who had successfully completed Graston certifica-tion level M-1. Using GT-1 tools, the SWEEP technique from the Graston manual was used. The SWEEP technique 'sweeps'

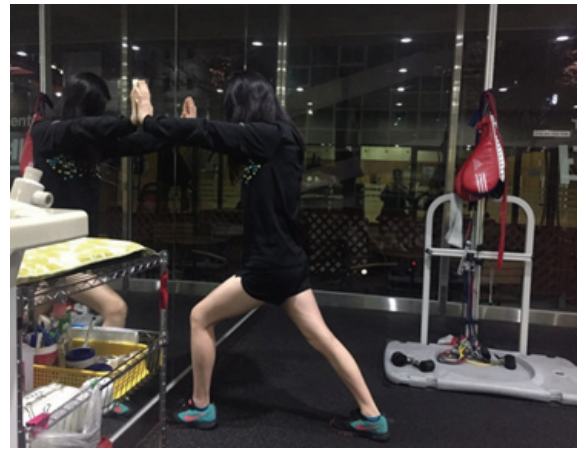

Fig. 3. Standing calf stretch.

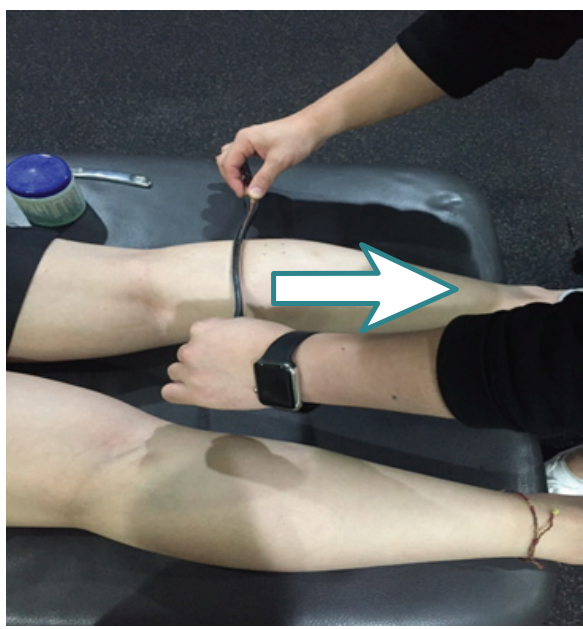

Fig. 4. Graston technique.

the soft tissue down, as if it is being pulled [18]. Massage cream was applied to the gastrocnemius muscle of the subjects, who were lying face down, and the SWEEP technique was then performed downwards from the popliteal region to the Achilles tendon for 60 seconds, 30 times in total (Fig. 3). The pressure on the gastrocnemius was set to VAS (Visual analog scale) 3 based on the subjects' statements [19].

Self-stretching was performed by placing both hands on a wall in the standing position while displacing the leg posteriorly and keeping the knee extended with the heels maintaining contact with the floor surface. This position was held for 30 seconds and was repeated two times (Fig. 4) [20]. The mediator constantly gave verbal 
Table 2. Comparison of Muscular Characteristics between the Two Groups before and after Intervention

\begin{tabular}{ccccc}
\hline & & Pre & Post & \\
& & \multicolumn{2}{c}{ Mean \pm SD } & \\
\cline { 2 - 4 } & Tone $(\mathrm{Hz})$ & $19.17 \pm 1.16$ & $17.28 \pm 1.62$ & $.000^{*}$ \\
GIASTM Group & Stiffness (N/m) & $331.07 \pm 30.09$ & $285.40 \pm 20.16$ & $.000^{*}$ \\
& MSRT (msec) & $.96 \pm .15$ & $1.03 \pm .14$ & $.004^{*}$ \\
& Relaxation Time (msec) & $15.81 \pm 1.85$ & $18.78 \pm 1.77$ & $.000^{*}$ \\
\hline \multirow{2}{*}{ Self-stretching } & Tone (Hz) & $17.75 \pm 1.32$ & $18.03 \pm 2.52$ & .676 \\
Group & Stiffness (N/m) & $300.60 \pm 31.77$ & $297.40 \pm 32.99$ & .194 \\
& MSRT (msec) & $1.04 \pm .11$ & $2.07 \pm 3.99$ & .325 \\
\hline
\end{tabular}

Comparison was performed by paired t-test

MSRT (time required for a muscle to recover after distortion)

${ }^{*} p<.05$, GIASTM: graston instrument-assisted soft-tissue mobilization

Table 3. Comparison of Average Difference Values in Muscular Characteristics between the Two Groups before and after Intervention

\begin{tabular}{|c|c|c|c|}
\hline & GIASTM & Self-stretching & \multirow{2}{*}{$p$} \\
\hline & \multicolumn{2}{|c|}{ Mean \pm SD } & \\
\hline Tone $(\mathrm{Hz})$ & $-1.88 \pm 1.45$ & $0.28 \pm 2.54$ & $.008^{*}$ \\
\hline Stiffness $(\mathrm{N} / \mathrm{m})$ & $-45.67 \pm 31.71$ & $-3.20 \pm 9.09$ & .359 \\
\hline MSRT (msec) & $.07 \pm .08$ & $1.04 \pm 3.93$ & $.000^{*}$ \\
\hline Relaxation Time (msec) & $2.97 \pm 2.02$ & $.42 \pm .71$ & $.000 *$ \\
\hline
\end{tabular}

Comparison was performed by independent t-test

MSRT (time required for a muscle to recover after distortion)

${ }^{*} p<.05$, GIASTM: graston instrument-assisted soft-tissue mobilization.

feedback so that the subjects could maintain the correct position.

\section{Statistical analysis method}

All measurement data were analyzed using SPSS 18.0 (SPSS 18.0, IBM Corp, USA). A paired t-test was used to compare the muscular characteristics of the gastrocnemius before and after the in-tervention in the GIASTM and self-stretching groups. An independent t-test was performed to compare the changes before and after the intervention between the two groups. The significance level was set to $a=.05$.

\section{Results}

The muscle tone and stiffness decreased significantly after the intervention in the GIASTM group $(p<.05)$, while the elasticity and MSRT increased significantly ( $p$ $<.05)$. Although muscle tone and elasticity were increased in the self-stretching group, the changes were not significant $(p>.05)$. Furthermore, the self-stretching group has an insignificant decrease in stiffness $(p>.05)$ and a significant increase in MSRT $(p<.05)$ (Table 2). Comparisons of the changes showed that the muscle tone, elasticity, and MSRT differed significantly between the two groups, except for stiffness $(\mathrm{p}<.05)$ (Table 3$)$. 


\section{Discussion}

The GIASTM group showed a significant decrease in muscle tone and stiffness and a significant increase in elasticity and MSRT. The self-stretching group showed only a significant increase in MSRT. The muscle tone indicates blood flow into the muscle, and a high level of muscle tone indicates a high level of pain and muscle overuse [21]. Stiffness, which represents the resistance level when the muscle shape is altered, is proportional to the muscle resistance [19]. Balle et al. reported that muscles with low stiffness could extend and absorb larger amounts of energy in response to an applied force, and were, therefore, relatively safer from damage [22]. Elasticity in-dicates that the muscle returns to its original shape; a lower elasticity level means more muscle fatigue. The GIASTM treatment greatly reduces the limitations to mobility caused by crystallized cross-links formed in the myofascia [23]. This treatment reduces muscle tension and increases the range of motion, which restores flexibility [19]. GIASTM is an effective treatment method for fibro-sis that reduces pain, rearranges tissues, and improves mobility [23]. In this study, significant de-creases in muscle tone and stiffness, as well as significant increases in elasticity, were observed in the gastrocnemius of the GIASTM group. The results indicate that a decrease in muscle fatigue would prevent muscle damage in athletes.

MSRT shows the time it takes for a muscle to recover after being distorted by external force or contraction [21]. Widmaier et al. reported that muscles shortened by fatigue or damage returned to a state with less tension after contraction, and the MSRT of these muscles became shorter [24]. In this study, a significant increase in the MSRT of the gastrocnemius was observed in both the GIASTM and self-stretching groups. On the other hand, a comparison of the two groups revealed a more significant increase in the MSRT in the GIASTM group. Therefore, GIASTM is more effective in recovering the gastrocnemius muscle from fatigue than self-stretching.

The limitations of this study are as follows. First, the subjects were athletes without pain or shortening of the gastrocnemius. Second, GIASTM and self-stretching were only applied for a maximum of one minute. Therefore, it is difficult to explain the changes in the muscular properties according to intervention time. Third, it was not possible to compare with other interventions other than self-stretching. Therefore, further studies should be conducted on athletes with pain or shortening of the gastrocnemius and the long-term effects of GIASTM.

\section{Conclusion}

The application of GIASTM to the gastrocnemius of athletes can significantly influence the muscle tone, stiffness, elasticity, and MSRT. Furthermore, self-stretching produced significant differences in MSRT. The GIASTM group showed significantly better outcomes, except for stiffness. Therefore, intervention using GIASTM will more efficiently prevent gastrocnemius damage and recovery from fatigue. This study suggests that GIASTM may be used to prevent a decrease in muscle perfor-mance due to gastrocnemius damage and contribute to the development of a rehabilitation pro-gram for athletes in clinical settings.

\section{References}

[1] Vieira ER, da Costa BR. Stretching to reduce work-related musculoskeletal disorders: a system-atic review. J Rehabil Med. 2008;40(5):321-8.

[2] Wong S, Ning A, Lee C, Feeley BT, et al. Return to sport after muscle injury. Curr Rev Musculo-skelet Med. 2015;8(2):168-75.

[3] Michael P. The BMA guide to Sports Injuries. British medical Association. 2013:136-7.

[4] Castellote-Caballero Y, Valenza MC, Puentedura EJ, et al. Immediate effects of neurodynamic sliding versus 
muscle stretching on hamstring flexibility in subjects with short hamstring syn-drome. J Sports Med. 2014; 1(1):8-15.

[5] Forman J, Geertsen L, Rogers ME, et al. Effect of deep stripping massage alone or with eccen-tric resistance on hamstring length and strength. J Bodyw Mov Ther. 2014;18(1):139-44.

[6] Johnson AW, Mitchell UH, Meek K, et al. Hamstring flexibility increases the same with 3 or 9 repetitions of stretching held for a total time of 90s. Phys Ther Sport. 2014;15(2):101-5.

[7] Whatman C, Cronin J, Nash M, et al. The acute effects of hamstring stretching and vibration on dynamic knee joint range of motion and jump performance. Phys Ther Sport. 2008;9(2):89-96.

[8] Fasen JM, O'Connor AM, Schwartz SL, et al. A randomized controlled trial of hamstring stretching: comparison of four techniques. J Strength Cond Res. 2009;23(2):660-7.

[9] Davis DS, Covert CA, Alexander MP, et al. Comparison of ballistic and static stretching on ham-string muscle length using an equal stretching dose. J Strength Cond Res. 2010;24(11):3008-14.

[10] Schaefer JL, Sandrey MA. Effects of a 4-week dynamic-balance-traning program supplement-ed with GIASTM(Graston Instrument-Assisted Soft-Tissue Mobilization) for chronic ankle instability. J Sport Rehab. 2012;21(4):313-26.

[11] Lee JH, Lee DK, Oh JS, et al. The effect of Graston technique on the pain and range of motion in patients with chronic low back pain. J Phys Ther Sci. 2016; 28(6):1852-5.

[12] Howitt S, Wong J, Zabukovec S, et al. The conservative treatment of trigger thumb using graston techniques and active release techniques. J Can Chiropr Assoc. 2006; 50(4):249.

[13] Hammer WI, Pfefer MT. Treatment of a case of subacute Lumbar compartment syndrome us-ing the Graston technique. J Manipulative Physiol Ther. 2005;28(3):199204.

[14] Bailey L, Samuel D, Warner M, et al. Parameters representing muscle tone, elasticity nd stiff-ness of biceps brachii in healthy older males: symmetry and withinsession reliability using the Myotonpro. J Neuro Disord. 2013;1:116.

[15] Leonard T. R, Herzog W. The history dependence of force production in mammalian skeletal muscle following stretch-shortening and shortening-stretch cycles. J Biomech. 2000;33(5):531-42.

[16] David A Jamadar, Jon A Jacobson, Sean E Theisen, et al. Sonography of the Painful Calf: Dif-ferential Considerations. American Journal of Roentgenology. 2002;179:709-16.

[17] Agyapong-badu S, Aird L, Bailey L, et al. Interrater reliability of muscle tone, stiffness and elasticity measurements of rectus femurs and biceps brachii in healthy young and older males. Working papers in the health sciences. 2013;1(4):1-11.

[18] Walker BF, Crothers AL, French SD, et al. Erratum to: Spinal manipulative therapy, Graston technique ${ }^{\circledR}$ and placebo for non-specific thoracic spine pain: a randomised controlled trial. Chi-ropr Man Therap. 2016;11;24-31.

[19] DH Kim, TH Kim, DY Jung, JH, et al. Effects of the Graston Technique and Self-myofascial Re-lease on the Range of Motion of a Knee Joint. J Korean Soc Phys Med, 2014;9(4):455-63..

[20] Marie A Johanson, Armstrong M, Hopkins C, et al. Gastrocnemius Stretching Program: More Effective in Increasing Ankle/Rear-Foot Dorsiflexion when Subtalar Joint Positioned in Pronation Than in Supination. J Sport Rehabil. 2015;24(3):307-14.

[21] Kim DH, Kim SK, Jung YJ et al. Measurement of low back muscle characteristic change using MyotonPRO in a long-term driving; pilot study. Korea institute of industrial engineers. 2015;4123-29.

[22] Balle SS, Magnusson SP, McHugh MP, et al. Effects 
of contract-relax vs static stretching on stretch-induced strength loss and length-tension relationship. Scand J Med Sci Sports. 2015;25(6):764-9.

[23] Fowler S, Wilson JK, Sevier TL, et al. Innovative approach for the treatment of cumulative trauma disorders. Work.
2000;15(1):9-14.

[24] Widmaier Eric P, Raff Hersel, Strang Kevin T, et al. Vander's Human Physiology: The Mecha-nisms of Body Function(12th ed). NY. 2010:250-91. 
